\title{
Technical Note: Direct Enzyme Immunoassay of Progesterone in Bovine Milk Whey
}

\author{
A. Comin, ${ }^{1}$ B. Renaville, ${ }^{1}$ E. Marchini,${ }^{1}$ S. Maiero, ${ }^{1}$ F. Cairoli, ${ }^{2}$ and A. Prandi ${ }^{1}$ \\ ${ }^{1}$ Dipartimento di Scienze degli Alimenti, Sezione di Fisiologia Veterinaria e Nutrizione, Università di Udine, Italy \\ ${ }^{2}$ Dipartimento di Scienze Cliniche Veterinarie, Università di Milano, Italy
}

\begin{abstract}
A simple extraction-free or direct quantitative ELISA for progesterone in bovine milk whey was developed. Whey samples are easy to collect, transport, and store. This method also allows for monitoring progesterone levels in cattle, which is important in reproductive management. The assay was designed to cover the concentration range 0.05 to $2 \mathrm{ng} / \mathrm{mL}$, and the sensitivity of the method was $1.5 \mathrm{pg} / \mathrm{mL}$. The intra- and interassay coefficients of variation were 8 and $12 \%$, respectively. A high correlation $(r=0.90)$ between ELISA and radioimmunoassay measurements of progesterone in the same milk whey samples was obtained. The method can be easily applied in practice because samples can be stored at room temperature $\left(22\right.$ to $\left.26^{\circ} \mathrm{C}\right)$ for $4 \mathrm{~d}$. Moreover, because analysis requires milk coagulation, that process can be initiated during transport by standard mail services to the laboratory. Upon arrival at the laboratory, whey can be kept refrigerated for $1 \mathrm{wk}$ before analysis. This tool is useful for monitoring luteal activity of dairy cows.
\end{abstract}

(Key words: progesterone, whey, milk, cow)

Abbreviation key: $\mathbf{R I A}=$ radioimmunoassay.

\section{INTRODUCTION}

Over the last $10 \mathrm{yr}$, milk yields of dairy cows have improved but reproductive performances have declined (Darwash et al., 1999). To achieve good reproductive efficiency, the calving interval should be around $1 \mathrm{yr}$ (Dijkhuizen et al., 1997). This requires the resumption of cyclic luteal activity within a few weeks after parturition. However, it is difficult to accurately determine when cows resume cyclic activity. The earliest epidemiological studies of postpartum ovarian dysfunction were based on rectal palpation (McLeod and Williams, 1991). However, more accurate and extensive investigations involve ultrasound examinations of the ovaries or re-

Received June 7, 2005.

Accepted August 24, 2005.

Corresponding author: Alberto Prandi; e-mail: fisiovet@uniud.it. peated determinations of blood progesterone concentrations (Savio et al., 1990; Lucy et al., 1991).

Measuring progesterone during estrous cycles is a useful diagnostic tool for the veterinarian and dairy producer. It allows cyclic activity monitoring, identification of estrus before insemination, and pregnancy exclusion diagnosis. The use of on-farm milk progesterone testing to prevent insemination errors significantly reduced the number of services per conception, and thus reduced insemination costs (Ruiz et al., 1989). Moreover, monitoring return to cyclicity of cows improves reproductive performance making use of the test economically justifiable even though Ruiz et al. (1992) showed that testing was more profitable in herds with low fertility and low efficiency of detection of estrus.

Monitoring progesterone levels in milk rather than plasma has the advantage of an easy sampling method, but is associated with several problems regarding sample preservation and the presence of varying fat content of milk samples. Foote et al. (1979) recommended use of a preservative when collecting milk. They also reported that when preservative is unavailable, whole milk can be assayed but special care should be taken. Hoffmann and Hamburger (1973) showed that presence of milk fat increased the progesterone concentration. Oltner and Edquist (1981) suggested that the progesterone concentration in defatted milk is independent of that in whole milk so milk could be collected at any time of day. To reduce possible errors caused by varying milkfat content, progesterone can be measured in defatted milk (Pope et al., 1976) or whey.

Problems of preserving samples can be resolved using the whey obtained after coagulating milk with rennet because it allows progesterone measurements on a matrix that is less sensitive to temperature variation and independent of milk fat concentration. The milk coagulation requires $30 \mathrm{~min}$ at $40^{\circ} \mathrm{C}$ or 2 to $3 \mathrm{~d}$ at room temperature $\left(22-26^{\circ} \mathrm{C}\right)$. This last solution allows transporting samples by standard mail to the laboratory. Upon arrival in the laboratory, whey can be kept refrigerated for $1 \mathrm{wk}$ before analysis.

Progesterone determination in whey samples using a radioimmunoassay (RIA) method has been described 
in previous reports from our laboratory (Prandi et al., 1994). This assay has been tested on more than 100,000 milk whey samples analyzed as part of the service provided to veterinarians. Radioimmunoassay, although extremely sensitive and simple, has the disadvantage of requiring special permits and generating radioactive waste that has a disposal cost.

The objective of this study was to validate a simple, sensitive, rapid, and direct (without solvent extraction) ELISA method to determine progesterone concentrations in milk whey samples, using a RIA method as a reference.

\section{MATERIALS AND METHODS}

\section{Sample Preparation}

Milk was collected at the start of milking directly into a straw (similar to a $500-\mu \mathrm{L}$ AI straw) in which $0.1 \%$ (wt/vol) microbial coagulating solution (rennet) had been previously dehydrated. Samples were transported by standard mail services to the laboratory within $24 \mathrm{~h}$. Upon arrival at the laboratory, samples were incubated at $40^{\circ} \mathrm{C}$ for $30 \mathrm{~min}$ to complete the clotting process. After centrifugation at $3000 \times \mathrm{g}$ for $10 \mathrm{~min}$ at $4^{\circ} \mathrm{C}$, straws were frozen $\left(-20^{\circ} \mathrm{C}\right)$ to solidify the fat, whey, and curd phases, and kept at $-20^{\circ} \mathrm{C}$ until required for analysis.

\section{ELISA Method}

The standard curve used progesterone (Sigma Chemical Co., St, Louis, MO) diluted in ethanol. Aliquots of this solution were dried and reconstituted in ELISA buffer (50 $\mathrm{m} M$ phosphate buffer, $\mathrm{pH}$ 7.4, $0.4 \%$ BSA, 0.5 $M \mathrm{NaCl}$ ) to prepare 6 standard concentrations ranging from 0.05 to $2 \mathrm{ng} / \mathrm{mL}$, as this range of concentrations includes concentrations of progesterone measured in whey using RIA (Prandi et al., 1994). Microplates (96 wells; Nunc Maxisorp, Roskilde, Denmark) were coated with $150 \mu \mathrm{L} /$ well of antirabbit-IgG antibody (kindly provided by $\mathrm{C}$. Tamanini and R. Renaville) diluted 1:6000 in coating buffer $(10 \mathrm{~m} M$ carbonate buffer, $\mathrm{pH} 9)$. After an overnight incubation at $4^{\circ} \mathrm{C}$, plates were washed 5 times with washing buffer (100 $\mathrm{m} M$ phosphate buffer, $\mathrm{pH} 7.4,1.54 \mathrm{M} \mathrm{NaCl}, 0.5 \%$ Tween 20$)$. Aliquots $(25 \mu \mathrm{L})$ of progesterone standards or whey samples were added to the microplate wells. The rabbit anti- $11 \alpha-\mathrm{OH}$-progesterone-hemisuccinate-BSA antibody produced in our laboratory shows cross reactivity with $11 \beta$-OH-progesterone, $46 \% ; 17 \alpha-\mathrm{OH}$-progesterone, $0.4 \% ; 20 \alpha-\mathrm{OH}$-progesterone, $0.04 \%$; testosterone, $0.08 \%$; cortisol, $<0.01 \%$; estradiol $17 \beta,<0.01 \%$; estradiol $17 \alpha,<0.01 \%$; and estrone, $<0.01 \%$.
Anti-progesterone antibody $(25 \mu \mathrm{L})$ diluted 1:30,000 in ELISA buffer was added along with $50 \mu \mathrm{L}$ of the progesterone-peroxidase conjugate (Fitzgerald, Concord, MA) diluted 1:2000 in ELISA buffer. Plates were incubated overnight at $4^{\circ} \mathrm{C}$, and washed 5 times in washing buffer to remove any unbound progesterone. The amount of bound conjugate was quantified by adding $200 \mu \mathrm{L}$ of chromogenic substrate $(119 \mathrm{~m} M$ citrate buffer $\mathrm{pH} 4,0.01 \% \quad \mathrm{H}_{2} \mathrm{O}_{2}, 0.1 \mathrm{mg} / \mathrm{mL} 3,3^{\prime}, 5,5^{\prime}$-tetramethyl-benzidine substrate). The plates were incubated for $30 \mathrm{~min}$ in darkness at room temperature $\left(24^{\circ} \mathrm{C}\right)$. The reaction was stopped with $2 \mathrm{M} \mathrm{H}_{2} \mathrm{SO}_{4}(50$ $\mu \mathrm{L}$ per well). Absorbance was read at $450 \mathrm{~nm}$ using a plate reader (model EL 311SX, software KC4, BioTek Instruments Inc., Winooski, VT).

\section{ELISA Validation}

Progesterone levels were determined in whey samples using RIA as described by Prandi et al. (1994). Accuracy was tested by the parallelism and recovery test. The parallelism test consisted of determining the deviation from the standard curve of a series of whey samples containing known amounts of progesterone. These samples were prepared by serial dilution of milk whey from a pregnant cow and whey from a cow in estrus. Test of linear regression was used to determine if whey and the standard progesterone curve deviated from parallelism. The recovery test was conducted to evaluate the system response to an increasing amount of progesterone standard added to a whey sample with low progesterone. The sensitivity of the curve was calculated as the interpolated dose of the response to a concentration of zero minus the statistical error. The interand intraassay precision of the method were expressed as the coefficients of variation (CV\%). The regression of ELISA and RIA results was used to derive the equation that best described the mathematical relationship between progesterone measured with the 2 analytical procedures. The assay was then applied to the profiling of estrous cycles of 10 Italian Frisona (Friesian) cows using milk samples collected daily (a.m. milking).

\section{RESULTS}

The parallelism between the whey dilution curve and the standard curve indicated that whey progesterone and standard progesterone react identically with the antibody, because a high correlation $(r=0.99)$ was observed between the concentrations obtained and those expected (Figure 1). The precision of the determinations over the range of concentrations tested (68 to $514 \mathrm{pg}$ / $\mathrm{mL}$ ) was equally high (CV\% $=6$ to 14$)$. Moreover, the concentrations obtained by diluting whey samples were 


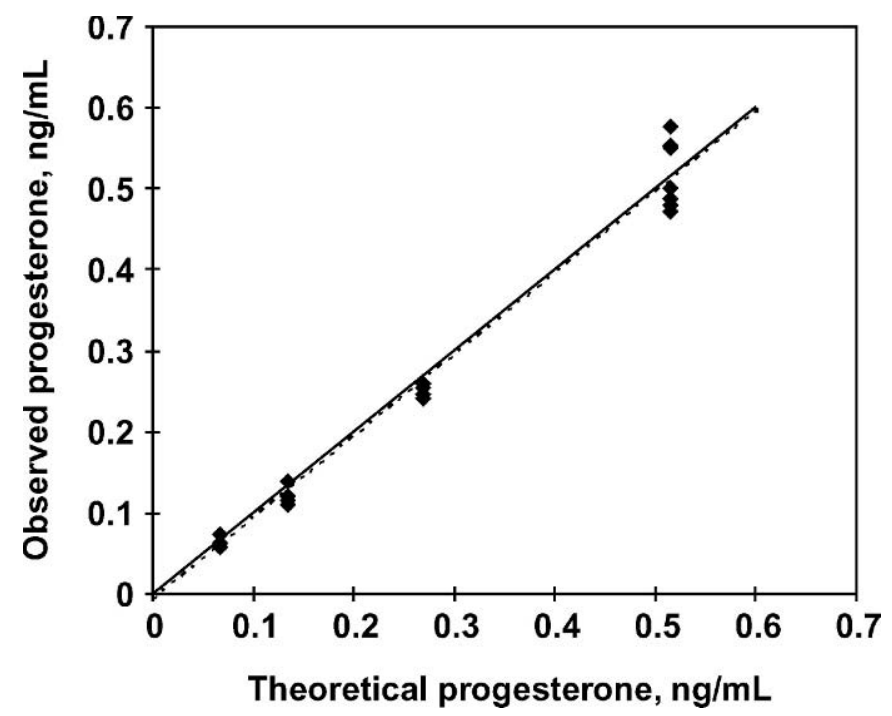

Figure 1. Relationship between whey progesterone curve and standard progesterone curve. Whey sample from a pregnant cow was diluted serially with whey from a cow in estrus and progesterone was measured in aliquots of diluted whey ( $)$ The correlation (-----) between standard values and whey samples was $\mathrm{y}=0.96 \mathrm{x}-0.0094, \mathrm{r}=$ 0.99 . The line (-) represents the equation $\mathrm{y}=\mathrm{x}$ (standard values).

comparable to those of the standard curve. Equations for the regression lines revealed a mean quantitative recovery of $94.2 \pm 2.6 \%$ (mean $\pm \mathrm{SEM}$ ). The coefficient of correlation was 0.99 (Figure 2).

The sensitivity of the method was $1.5 \mathrm{pg} / \mathrm{mL}$. A whey sample showed inter- and intraassay coefficients of

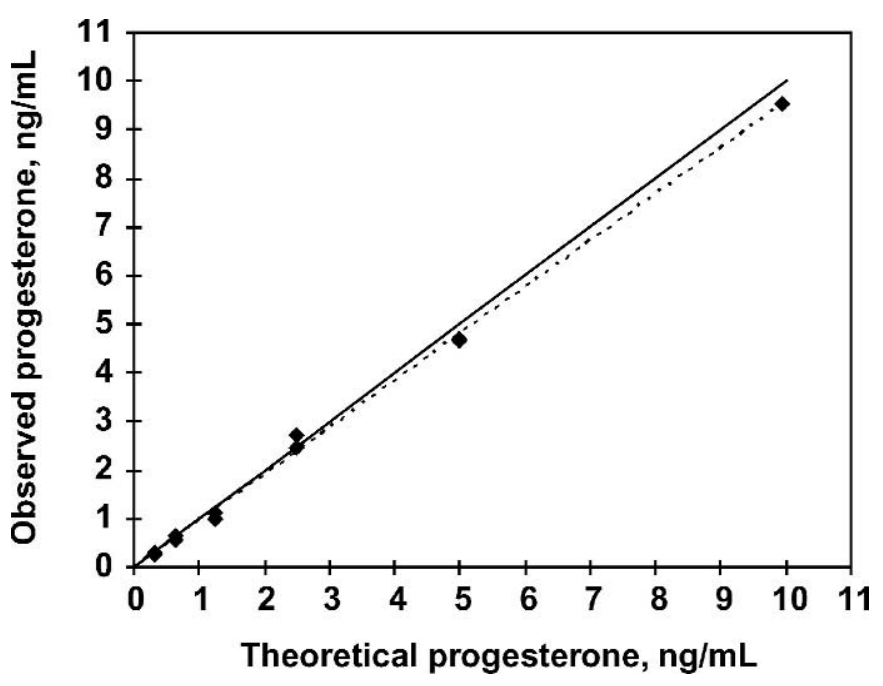

Figure 2. The recovery test was used to evaluate the response of the system to an increasing mass weight of progesterone standard. The correlation between standard values and whey samples $(\bullet)$ was $\mathrm{y}=1.00634 \mathrm{x}-0.0074, \mathrm{r}=0.99$, as illustrated by the dashed (-----) line. The continuous line (-) represents the equation $\mathrm{y}=\mathrm{x}$. variation, in repeated determinations, of 8.7 and $12 \%$, respectively.

Progesterone concentrations determined in the same samples using the RIA and ELISA methods were similar and highly correlated $(\mathrm{r}=0.95)$. Regression of the ELISA (y) on the RIA (x) data produced the equation: $\mathrm{y}=1.20+0.87 \mathrm{x}, \mathrm{r}=0.90$.

The mean trend shown by progesterone concentrations determined in milk whey during the estrous cycle is provided in Figure 3. Progesterone levels during diestrus and estrus were $1010 \pm 118 \mathrm{pg} / \mathrm{mL}$ and $209 \pm 23$ $\mathrm{pg} / \mathrm{mL}$ (mean $\pm \mathrm{SEM}$ ), respectively. Progesterone concentrations below $300 \mathrm{pg} / \mathrm{mL}$ were considered appropriate for classifying the animal as not pregnant at 20 to $21 \mathrm{~d}$ after insemination.

\section{DISCUSSION}

The method developed here could easily be applied in practice because it is not invasive and not limited by storage temperature during transport to the laboratory. Its ability to provide discriminatory reference progesterone concentrations and progesterone profiles suggests that it would be a useful tool for farmers, inseminators, and veterinarians. Samples can be stored at room temperature for a few days, making transport and storage easy. The determination of progesterone concentrations in milk whey samples using the direct ELISA procedure is feasible and reproducible. The dilutions tested indicated the high sensitivity and reproducibility of results within the normal range of hormone concentrations at different reproductive stages. Overlapping of the dilution curve and standard curve indicates the method's high specificity and lack of interfering factors.

The ELISA technique described here showed high correlation with RIA and proved to be more sensitive than our RIA quantification method and other ELISA procedures (Munro and Stabenfeldt, 1984; Hatzidakis et al., 1993; Del Vecchio et al., 1995).

This procedure is already used as a tool to evaluate the resumption of ovarian activity, cyclicity, and determining pregnancy, and is suitable for early assessment of the efficiency of fertility treatments.

\section{ACKNOWLEDGMENTS}

The authors thank A. Cappa (Associazione Allevatori, Vicenza) for technical support, R. Renaville (Gembloux Agricultural University, Belgium), and C. Tamanini (University of Bologna, Italy) for providing the antirabbit-IgG antibodies. This research was supported by a MURST Cofin grant (2005). 


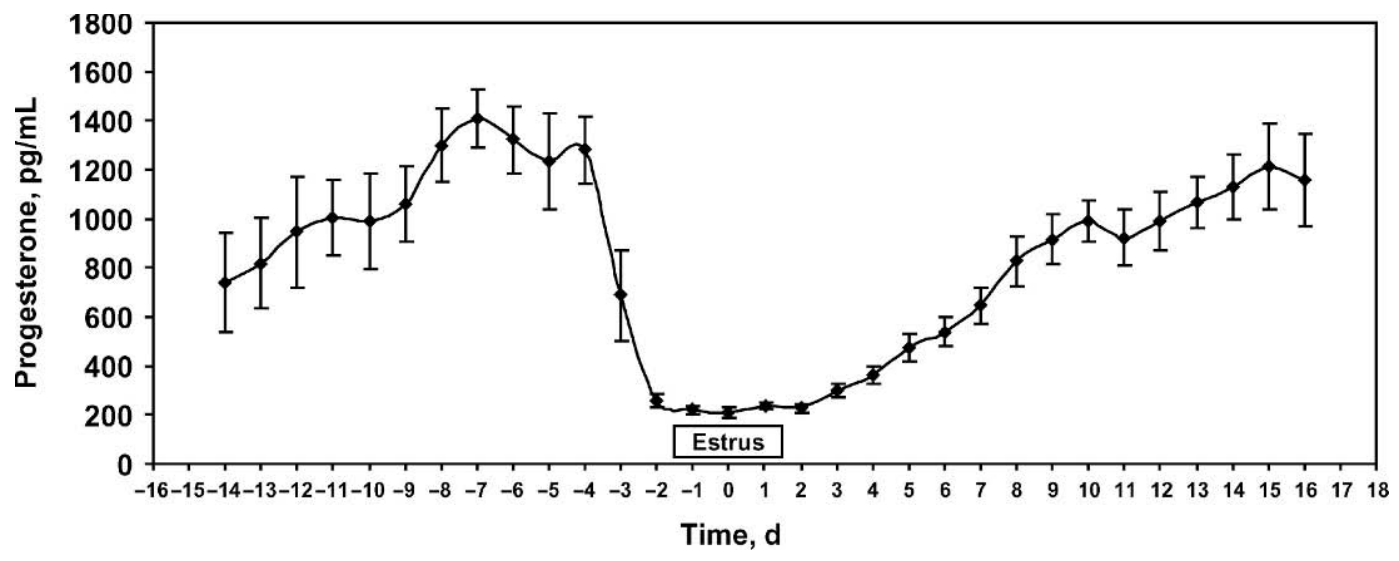

Figure 3. Profile of progesterone concentration for 10 cows during estrous cycle (mean \pm SEM) as determined daily by enzyme immunoassay.

\section{REFERENCES}

Darwash, A. O., G. E. Lamming, and J. A. Wooliams. 1999. The potential for identifying heritable endocrine parameters associated with fertility in postpartum dairy cows. Anim. Sci. 68:333-347.

Del Vecchio, R. P., W. D. Sutherland, and M. L. Connor. 1995. A solid-phase enzyme immunoassay for the determination of progesterone in bovine, porcine and ovine plasma. Can. J. Anim. Sci. 75:525-529.

Dijkhuizen, A. A., R. B. M. Huirne, A. W. Jalvingh, and J. Stelwagen. 1997. Economic impact of common health and fertility problems. Pages 41-58 in Animal Health Economics. Principles and Applications. A. A. Dijkhuizen, and R. S. Morris, ed. University of Sydney Press, Sydney, Australia.

Foote, R. H., E. A. Oltenacu, H. L. Kummerfeld, R. D. Smith, P. M. Riek, and R. K. Braun. 1979. Milk progesterone as a diagnostic aid. Br. Vet. J. 135:550-558.

Hatzidakis, G., A. Stefanakis, and E. Krambovitis. 1993. Comparison of different antibody-conjugate derivates for the development of a sensitive and specific progesterone assay. J. Reprod. Fertil. 97:557-561.

Hoffmann, B., and R. Hamburger. 1973. Progesterone in der milch: Radioimmunologische bestimmung bezichungen zur gelbkorperfunktion und milchfettkonzentration. Zuchthygiene 8:154-162. [In German]

Lucy, M. C., C. R. Staples, F. M. Michel, and W. W. Thatcher. 1991. Energy balance and size and number of ovarian follicles detected by ultrasonography in early postpartum dairy cows. J. Dairy Sci. 74:473-482.

McLeod, B. J., and M. E. Williams. 1991. Incidence of ovarian dysfunction in postpartum dairy cows and the effectiveness of its clinical diagnosis and treatment. Vet. Rec. 128:121-124.

Munro, C., and G. Stabenfeldt. 1984. Development of a microtitre plate enzyme immunoassay for the determination of progesterone. J. Endocrinol. 101:41-49.

Oltner, R., and L. E. Edquist. 1981. Progesterone in defatted milk: Its relation to insemination and pregnancy in normal cows as compared with cows on problem farms and individual problem animals. Br. Vet. J. 137:78-87.

Pope, G. S., I. Majzlik, P. J. H. Ball, and J. D. Leaver. 1976. Use of progesterone concentrations in plasma and milk in the diagnosis of pregnancy in domestic cattle. Br. Vet. J. 132:497.

Prandi, A., M. Motta, A. Tondolo, and C. Rossi. 1994. Evaluation of the reproductive efficiency of Simmental and Friesian cows farmed in Friuli (north-east Italy) by the analysis of progesterone levels. Theriogenology 42:65-78.

Ruiz, F. J., P. A. Oltenacu, and R. D. Smith. 1989. Evaluation of onfarm milk progesterone tests to determine nonpregnant cows and to prevent insemination errors. J. Dairy Sci. 72:2718-2727.

Ruiz, F. J., A. Oltenacu, and R. D. Smith. 1992. Cost-benefit evaluation of on-farm milk progesterone testing to monitor return to cyclicity and to classify ovarian cysts. J. Dairy Sci. 75:1036-1043.

Savio, J. D., M. P. Boland, N. Hynes, and J. F. Roche. 1990. Resumption of follicular activity in the early postpartum period of dairy cows. J. Reprod. Fertil. 88:569-579. 